INTERNATIONAL HIGHER EDUCATION Number 74 Winter 2014

Pages 2-3

\title{
The Need for Research and Training for the Higher Education Enterprise
}

Prepared by the Boston College Center for International Higher Education in consultation with participants in the first International Higher Education Research and Policy Roundtable Shanghai Jiao Tong University, November 2-3, 2013.

This "Shanghai Statement" is intended to highlight the need for "thinking capacity," data, policy analysis, and professional training for tertiary education worldwide. We are convinced that both institutions and systems, faced with a myriad of challenges and crises, require thoughtful leadership and data-based analysis. We can no longer rely on amateur management and ad hoc solutions to unprecedented problems.

\section{THE CONTEXT}

Postsecondary education is central to the global knowledge economy, as well as to both social mobility and workforce development worldwide. Vast investments are being made in higher education across the globe-developed countries spend 1.6 percent of the gross domestic product while emerging economies allocate somewhat less. Global enrollments approach 200 million. Tertiary education has become a major policy arena in most countries, because of its importance for educating a skilled workforce for the knowledge economy, social mobility, and the production and dissemination of research. Governments, the private sector, and academic institutions themselves require both data and policy guidance to adapt to a changing environment. 
In a few countries, a field of higher education studies has emerged to serve these needs. Data are collected by governments and other agencies. Research is undertaken to provide guidance for policy and practice at the national and international levels. Centers and institutes, located mainly in universities but also in government agencies or in private organizations, have been established. This developing field is so far limited to a fairly small group of countries.

Higher education requires professional management. Although only a few countries currently provide such training, there has been recognition, again in a small group of countries, that academic institutions, now in many cases large and bureaucratic entities, require professional management. Programs have been established to provide training for those involved in university service and management, including in some cases the top leadership of academic institutions.

The field of higher education needs to expand worldwide and requires careful attention and development-if the tertiary sector is to be effectively managed and led-and ultimately to deliver desired results for stakeholders. Data and analysis are required if informed decisions are to be made. Training and education are needed for the rapidly expanding cadre of higher education professionals. Research is needed to better understand the nature of the academic enterprise-institutionally, nationally, and globally—and the complex economic, political, pedagogical, and social issues central to higher education. 


\section{NECESSARY INFRASTRUCTURES}

Higher education requires a range of institutions and infrastructures and, most importantly, a cadre of qualified researchers, scholars, and professors, to provide the research, analysis, and training needed by an expanding and increasingly complex and sophisticated higher education enterprise. Among them are the following:

- Research centers: Building and maintaining research capacity in higher education requires dedicated centers or institutes. Interdisciplinary in nature, centers are probably best located in universities. They require qualified staff with deep expertise on higher education. Such centers may be attached to graduate training programs in universities that bring motivated students to assist with research work and the stimulation of an academic environment. Adequate size, scope, and dedicated budgets are necessary.

- Universities must assign staff to respond individually to prospective students, with information and assistance, during the admissions process. This will not be inexpensive, but if some of the budget now on agents can be redirected to this task, the funds will be well spent.

- Training programs: Higher education administration requires professionalization in the era of mass enrollments and increasingly large universities worldwide. Professionalization means training programs in higher education management, leadership, and in specialized areas of academic life—such as research management, quality assurance, financial affairs, or student development. Some of these may be degree programs at 
the master's or doctoral level, as is common in the United States. Some countries offer management degrees in higher education administration, as is common in the United Kingdom-although universities cannot be equated with other kinds of business enterprises. Shorter programs and courses focusing on university management and other higher education issues may also be useful.

- Institutional research and statistical data: Academic institutions of all kinds and higher education systems need a strong research capacity and the means of data collection. Often called institutional research, universities in a growing number of countries collect and analyze data about their own characteristics, policies, and results with the aim of effective decision making and planning. National higher education systems and governments also require good statistics and analysis. Good data are often unavailable, hindering both research and effective decision making.

- International and regional centers: In a globalized world, comparative and international data and analysis are crucial. This is particularly true since academic institutions and systems are themselves increasingly globalized. At present, there is no international organization with the capacity or interest to systematically collect and analyze data on a broad range of higher education themes, including basic statistics about institutions, systems, and trends. The same can be said for world regions. Further, international organizations can provide "thinking capacity" for 
considering policy issues and other matters in a broad comparative framework.

- Government must increase support to education information centers in the primary sending countries to provide on-site information with welltrained professional staff who can offer workshops and guidance to prospective students.

- Specialized organizations and centers: As higher education has become complex and specialized, the need for specialized knowledge and analysis in, for example, fields such as student affairs, internationalization, or academic administration, has become necessary. Organizations focused in specialized areas may be useful in larger countries, and on a regional and international basis, as well.

\section{The Policy EnVironment}

Higher education faces a myriad of challenges and there are many enduring themes of policy and practice that deserve additional in-depth research and analysis. While both diverse and requiring a range of approaches in terms of research and analysis, these topics deserve the attention of the higher education community:

- the implications of globalization-cross-border initiatives, international student flows, the impact of global inequalities, and related themes;

- challenges of quality and equity in higher education; 
- governance-what are the best models of governance for the era of massification and declining public resources? What is effective in practice?;

- systems-how are academic systems organized to meet the needs of massification and the global knowledge economy?;

- private higher education, privatization, commercialization, and related issues; and

- finally, the impact of higher education research on higher education, its funding, its relevance to policy and practice, and the means of sustaining and communicating research findings and analysis to both institutions and policymakers.

\section{COMMITMENT TO THE FUtURE}

Postsecondary education, a central element of the emerging global knowledge economy and increasingly important for both social mobility and workforce development worldwide, requires professional expertise, a knowledge base, relevant research on key issues, and training for professionals responsible for academic institutions and systems. Higher education centers and programslinked with policymakers in government, the private sector, and in academeare necessary for the success of the enterprise.

The effectiveness of higher education centers and programs, however, hinges on their ability to:

- engage in a robust and relevant ongoing dialogue with colleagues and counterparts in the policymaking sphere; 
- cultivate successive generations of talented young researchers who share an appreciation for, and commitment to, rigorous scholarship designed to enable thoughtful, data-driven decision making; and

- train academic leaders and professional administrators to manage tertiary education institutions and systems in an increasingly complex environment.

Thoughtful leadership, future-oriented planning, and a sustained commitment to the crucial mission of higher education research as a key ingredient for effective policy formulation and implementation will be needed more than ever in the coming years. All relevant stakeholders should recognize this fundamental dynamic between research, policy, and practice, and contribute substantively to the realization of its full potential. The future of higher education hangs in the balance.

\footnotetext{
Note:

Meeting in Shanghai, China, on November 2 and 3, 2013, the first international round table of directors of higher education centers from around the world along with key higher education policy specialists deliberated on the themes discussed in this statement. This document reflects in general the thinking of 33 research and policy professionals concerning the future development of the field of higher education research, policy, and training - at a crucial turning point for tertiary education globally. The workshop was organized by the Boston College Center for International Higher Education and Innovation, Higher Education and Research for Development (IHERD), an initiative of the Swedish International Development Agency (SIDA), with the collaboration of the Graduate School of Education at Shanghai Jiao Tong University. Funding was provided by SIDA and administered by SANTRUST, a South Africa-based NGO.
} 